\title{
Vulnerability to Brain-Drain among Academics in Institutions of Higher Learning in Ethiopia
}

\author{
Tesfaye Semela \\ Research Fellow of the Alexander von Humboldt Foundation, University of Tübingen, Germany \\ $\&$ \\ Institute of Education, Research and Training, Hawassa University, Ethiopia \\ E-mail: tesfayesem@yahoo.com
}

\begin{abstract}
This study investigated the extent, causes, and correlates of vulnerability to brain-drain among Ethiopian academics in higher education institutions (HEIs). The sample constituted a total of 103 faculty members (Females 9.3\% and Males 90.7\%) drawn from three colleges and four faculties affiliated to the Debub University. Data were collected through self-reported measures assessing vulnerability to brain-drain (external brain-drain conceptualized as intention to remain in a western country given that they would have opportunities for further study or research; and internal brain drain defined as a brain circulation within the country), affective job characteristics (job satisfaction and organizational commitment), and work environment factors. The results show that affective job characteristics and work environment variables significantly predicted vulnerability to internal brain-drain. While external brain drain is associated with vulnerability to internal brain drain and organizational citizenship behavior (OCB). A closer investigation into the prominence of the pull and push factors further disclosed that working condition and the salary are the outstanding ones. Implications of the findings for policy making are also discussed.
\end{abstract}

Keywords: Brain drain, Internal brain drain, Working conditions, University, Ethiopia

\section{Introduction}

The migration of Ethiopian academics to industrialized nations is a very recent phenomenon. Available studies on its historical development documented that Ethiopian scholars were less comfortable to live outside their country (e.g., Teferra 1992; Shinn 2002). Hence, until the mid 1970s, brain drain had never been considered a threat to socio-economic development in general, and to the development of higher education in particular. Similar to other countries south of the Sahara, the frequently given explanation as to its causes has been intolerance to divergent political views including critical attitude towards the state on the part of the academic community (e.g., Adebayo 2010; Zeleza 2004; Sall et al. 2003; Miwiria 2003). Consistently, the Military Regime that ruled Ethiopia from 1974 to 1991 sets one of the most notorious examples in the African continent. It is public knowledge that the horrible experience of the Red Terror chased away particularly the highly educated and skilled academics and experienced professionals. There is evidence to indicate that the period saw a huge outflow of the Ethiopian intelligentsia to the West and other industrialized countries (e.g., Aredo 2000; Teferra, D., Shinn 2002). Paradoxically, however, after the change of government, the magnitude of brain drain did not show a sign of decline. Instead, it continued with a renewed impetus inflicting considerable damage to the economy and of the higher education system via taking away the most able and badly needed human capital. Needles to argue, today, more than ever, higher education institutions in Ethiopia are feeling the pain of the migration. To be fair, it is not only external brain drain which has been posing a real threat to tertiary education in terms of retaining able academics, but also the lacerative jobs created by the flourishing private sector and NGOs (Teferra 2000).

Despite this alarming trend, however, studies over the last several years seem to be restricted around human resource issues of schoolteachers. These studies, among other things, raised problems related to teacher commitment and turnover (e.g., Olango \& Semela 2000; Semela 2003), teacher stress (Wole 2002), and extra-role behavior (Semela 2005). However, apart from limited information on antecedents of turnover (e.g., Semela 2004) among academics and professionals, the issue of brain drain received little empirical attention though anecdotal evidence suggest that Ethiopia is one of the hardest hit in Africa. Notwithstanding the paucity of data, available literature on the subject is enough to depict the disturbing trend (NASAC 2005). By way of 
scrutinizing the pattern of staff mobility in Ethiopian context, it can be argued that internal brain drain is as threatening as external brain drain. The explanation is that internal brain drain has been eroding the limited human capital reserve available in the public sector, particularly in higher education institutions owning to the widening job opportunities in the private sector and the proliferation of NGOs (e.g., Semela \& Ayalew 2008; Teferra 1992; 2000).

More than ever, since the turn of the $21^{\text {st }}$ Century the migration of academics has posed a serious challenge to the expanding HE system which is grappling with new social demands. In some cases, academic units within HEIs are on brink of collapse due to the already compromised academic standards resulted from the exodus of better qualified and experienced staff. Therefore, it is the purpose of this paper to look into the factors underpinning internal and external brain drain to suggest possible measures of addressing the problem.

\subsection{Economic, social, and educational context}

Ethiopia's total population is estimated to be 82.8 million in 2009 and is growing at rate of $2.6 \%$. Economically, Ethiopia is predominantly dependent on agriculture with $80 \%$ of the population living in rural areas while the industrial sector shares only $12 \%$ of GDP (Economy Watch 2010). The average GDP grew by 10-11\% continuously between 2006 and 2009. Ethiopia's GNP per capita currently stands at USD 361 which is still below the sub-Saharan average of USD 480. Though the adult literacy rate is lower than most countries in the region (i.e. only $36 \%$ is literate), significant achievements have been registered in the formal education sub-sector. Accordingly, over the last decade net enrollment at primary level has been steadily increased to embrace $83 \%$ (Male $=86 \%$ and Female $=80.7 \%$ ) of the eligible age group, while secondary education enrolls about $13.8 \%($ Female $=12.2 \%$ and Male $=15.4 \%)$ and tertiary education gross enrolment rate (GER) reached from less than one per cent to $4.8 \%$ (Females accounting for about $24.1 \%$ of 263,000 total undergraduate enrolment in HEIs in 2007/8) in 2007/8 (MoE 2009). Notwithstanding the speed with which the higher education grew over the last decade, access to university education is among the lowest in sub-Saharan Africa.

The Federal Democratic Republic Government of Ethiopia (FDRGE) has embarked on ambitious a higher education expansion project allocating its substantial budget which amount to $23 \%$ of the total earmarked for the education sector (ESDP II: 2002-2005). Thus, by the end of 2005, enrollment has increased from 35, 000 to 80,000 at undergraduate level and from 1,350 to 6,000 at graduate level. In 2007/8 the total undergraduate enrollment in private and public universities reached 263,001 [Female $=63,317(24.07 \%)$, nearly threefold of the total enrollment back in 2003/4 (see: MoE 2009: 60). However, it is feared that staff shortage would be one of the critical challenges confronting this huge enterprise (World Bank 2003; Semela 2004). As a short term measure, recruiting volunteers and employing expatriate academics have been going on since late 1990s. In the 2003 academic year alone, about 382 expatriates were employed including 268 Indians, 49 Cubans, 45 Nigerians, and VSO volunteers from the United Kingdom to mitigate the mounting staff shortage. As recently as 2007/8, the percentage of expatriates reached 9.3\% $(\mathrm{n}=538)(\mathrm{MoE} 2009)$. To date, to ensure the rapid expansion, recruiting staff notably from India and African countries has been intensified. In spite of the increasing demand for experienced people with an advanced university degree, there is little evidence of curtailing the threat posed by brain drain among local academics. Apparently, the quality of the work environment and the salary structure seems to hold little promise either to attract new people or retain those who are already there (e.g., Semela \& Ayalew 2008).

Looking at the magnitude of the human capital outflow from a single institution such as the Addis Ababa University, in the face of sweeping expansion of the higher education, the instances depict merely the "tip of an iceberg' of impediments. Evidently, this issue received limited research attention than it would have surely deserved. This study is, therefore, an attempt to investigate the role of work environment, salary, and job-related affective factors in encouraging or discouraging internal or external brain drain among Debub University (recently renamed Hawassa University) faculty members.

\section{A Glimpse at Earlier Research}

According to Shinn (2002), the term "Brain-drain" was coined by the "British Royal Society" to describe the outflow of scientists to the United States and Canada in the 1950s and 1960s. The coining of the term was, thus, associated with a massive migration of educated people of European origin in the 1960s primarily British, German and Canadian scholars to the USA (Teferra, D. 2000). While the notion of brain drain signifies the migration of highly skilled and educated people to industrialized nations, the mobility of academics out of HEIs without crossing their national boundary is referred as internal brain-drain (Teferra, 2000). On the other hand, even though internal brain drain negatively affects the sending organization/institution in terms of depleting its 
human resource capacity, there has been little interest for a scholarly research as opposed to what is referred as external brain drain.

\subsection{Magnitude of Africa's brain drain}

Research on the situation of brain-drain in developing countries in general and that of sub-Saharan Africa (SSA) in particular came out with assortment of factors. Shinn (2002) documenting the magnitude of brain drain from developing countries indicated that, in 1990-1991 about 79\% of $\mathrm{PhD}$ recipients in science and technology from India and $88 \%$ of those from China were still working in the USA until 1995 . He further noted that $23 \%$ of the medical personnel in the USA earned their credentials in a foreign country and the share of immigrants of African origin reported to have steadily increased. Talking about sub-Saharan Africa, Shinn documented that more than 2000 Nigerian doctors and about 10,000 academics are employed in the USA alone. Moreover, there are more Sierra Leonean doctors in Chicago than in all of Sierra Leon while Ghanaian doctors account for about $20 \%$ share of all doctors in New York City. Shinn concludes that there are more African born scientists and engineers working in the USA than there are in Africa. Regardless of the scale of migration, some scholars argue that brain drain can be changed into brain gain or brain circulation (e.g., Adebayo 2010; Saxenian 2005; Teferra, D. 2004). Based on success stories of some American educated Indian and Chinese Diaspora professionals, Saxenian (2005) argue that brain circulation is achievable. The African scenario seems to hold limited promise at least, in terms of mobilizing its resources to achieve the same degree of success as their Asian counterparts in the foreseeable future. The critical bottleneck is the digital gulf that separated Africa from the Western and industrialized world, not to mention the difficulties of erratic electric power supply and limited ICT infrastructure and facilities.

Specifically focusing on Ethiopia, many researchers agree that brain-drain is a recent phenomenon (e.g., Shinn 2002; Teferra 1992; 2000; Aredo 2000; World Bank 2003). Its beginning is largely attributed to the advent of a new Government composed of different groups of the army and police officers following a protracted political confrontation spearheaded chiefly by students. The new military junta committed untold atrocities against the best and the brightest segment of the young generation including seasoned intellectuals under the banner of establishing the new socialist Ethiopia. The subsequent Red Terror orchestrated by the same, however, was the final blow to the hopes and aspiration of academics to work in their own country. As a result, until the mid 70s brain-drain was not taken seriously as a potential danger to the country's development. During the Military era from 1980 to 1991 , of 22,700 students sent abroad, only 5,777 or about 25 percent returned to Ethiopia. In a wider timeframe extending between 1968/69 and 1995/1996, Aredo (2000) found that among total that were went abroad, 35\% failed to return. A similar survey on 135 instructors at Addis Ababa University and Kotebe College of Teacher Education, Teferra (1992) found that between early 1970s and mid 1980s, almost half as much as those who were sent abroad did not return. Based on reports of the Academic Vice President Annual Report of 1983/84 academic year, it was noted that out of 300 academic staff of Addis Ababa University that were granted study leave in previous years, only 22 returned (Teferra 1992). Based on two decades academic staff mobility, Teferra, D. (2000) documented that out of about 600 academic staff sent abroad over a period of two decades, only a third came back. Particular instances include the cases of the Departments of Mathematics and Physics of Addis Ababa University, which in less than a decade lost 18 and 15 academic staff respectively having been sent for PhD training (Teferra, D. 2000). With the exodus of experienced and skilled academics, particularly of those from science and technology has left the universities with not only with less qualified staff, largely composed of graduate assistants (e.g., Shibeshi, Mekonnen, Semela \& Endawoke 2009), but also without institutional leaders and mentors (Adebayo 2010) to the young and inexperienced. The already depleted reserve of human capital in these fields further overstretched beyond its natural limit due to the exploding student enrollment and new academic programs (Semela 2004).

The fact that the exodus of high caliber academics does not seem show any sign of declining after the liquidation of the dictatorial regime has been frustrating for most observers. Available studies (e.g. Teferra, S. 2000; Aredo 2000) confirm a discouraging trend in the migration of academic staff particularly from Addis Ababa University even though the scenario could be much worse if one considers college campuses that are geographically removed from the capital. For most concerned people, lack of attention in addressing the problem on the one hand, and the utopia among of young professionals to "Go West" (Teferra, S. 2000) and remain there on the other, has been a source of discontent. Here, it is revealing to cite what Aredo (2000) has said to depict the level of frustration: ...Today the motto is to flee Ethiopia, and change your own life; look after your selfish interest. The majority of the elite envisage no prospect for this country. (p. 11).

Aredo seem to suggest, at least implicitly, that young Ethiopian scholars are becoming increasingly self-centered and less patriotic. Even though studies focusing on brain drain in developing countries, underscore among other 
things, the effect of political persecution and intolerance, unfavorable working conditions and lack of academic freedom (e.g., Shinn 2002; Zeleza 2004), I would, however, argue that this time around presenting "political persecution" as cause of external brain drain seems to be less important than it used to be few decades ago. For instance, Seithi (1999) who investigated brain drain in Ethiopia indicated that among those who left their country, $30 \%$ went for professional development and further studies but it was only $7 \%$ that left for political reasons particularly after the fall of the Military Government. A neutral person would not claim that political persecution has been the single most important reason for Ethiopian scholars to flee their country though one cannot rule few isolated incidents. Admitting that the political environment is not as poor as the time Red Terror, Shinn he identified the pertinent "push" and "pull" factors that are more or less responsible to the alarming trend of brain-drain. According to Shinn, the Push factors include: (1) poor human right practices, (2) political and/or arbitrary arrest coupled with a backward court system (3) intolerance of political dissent (4) lack of academic freedom (5) civil conflict and the ravage of war (6) Illegal regime change and favoritism based on ethnic affiliation. Shinn went so far as to argue that even though these factors apply to most countries in sub-Saharan Africa, some of the above reasons fit Ethiopia as well. The other push factors are much to do with what Shinn referred as a "basket of economic reasons". These include: (7) Week economy, high unemployment, low salaries and wages, poor working conditions, and lack of research fund. In agreement with Shinn (2002), who attributed Ethiopia's brain to a basket of economic reasons, similar studies by African scholars (e.g., Obong 2004; Mohamoud 2005) capitalize on the role of pecuniary rewards.

In Uganda, Obong (2004) based on a survey on academic staff at Mekerere University concluded that making money has been taking precedence over institutional vision and commitment. The trend suggest that most young people are preoccupied with "opportunities of the West" and there seems to exist little discernable difference between the "better educated" and the less or non-educated in terms of feeling a sense of responsibility to one's own country when it comes to migrating to developed world. Hence, it would be unwise to anticipate an exceptional sense of patriotism from those who managed to get employment in higher institutions as long as, they belong to the same generation citizens who are victims of the pervading "money culture" (Obong 2004) and obsession about material gains that result from it. Hence, it is easy to decipher the absence of a solid career-plan and affective attachment to their employing institutions. These state of affairs forces one to raise the question: If at all, faculty members are emotionally attached to their institutions? And to what extent these affective characteristics linked to their degree of vulnerability to brain drain?

According to the forgoing discussion, it appears that the factors underpinning brain drain shifting from political to more economically induced, quality of workplace-triggered, and/or mediated by affective organizational factors. As it stands, the Ethiopian HEIs are victims of both kinds of brain drain. This paper attempts to uncover some of these factors that explain intent or non-intent to (a) leave academia to join other organizations within Ethiopia (internal brain drain), and (b) intention to stay on in a Western country if provided opportunities to go there for a further training or research (external brain drain).

Against the background of the above analyses, the present study seeks to find answers to the following questions:

- Do internal and external brain drain influenced by similar set of variables which included work environment, salary, and affective job characteristics?

- If salary, work environment, and affective job characteristics can play a role in impinging on internal and external brain drain what is their relative contribution in the predicative relationship?

- What are the "push" factors responsible of internal brain drain?

- Which "Pull" factors are salient for external brain drain?

\section{Research Design}

\subsection{Sample}

The sample was drawn from all facilities and colleges of Debub University. The affiliated colleges are located at three different places. Namely: Awassa, Dilla, and Wondo Genet. Awassa hosts two colleges - (i.e. Awassa College of Agriculture and Awassa College of Health Sciences) and three other faculties i.e. the Faculties of Social Science and Natural Science, and the Faculty of Technology). Dilla hosts the Dilla College of Teacher Education; and Wondo Genet hosts the College of Forestry. The target population (focused only on the local academic staff) was expected to have 302 faculty members (Debub University Ten Year Strategic Plan, Draft Document 2003). Of the total, 124 (41.1\%) were randomly given the questionnaires for volunteering to 
participate in the survey. Overall, 103 respondents returned usable questionnaires. The response rate was $83 \%$ to make it quiet acceptable to continue the analyses (Wiersma 2000). Hence, the sample was made up of $34.1 \%$ $(\mathrm{N}=103$; males $90.7 \%$ and females $9.3 \%$ ) of the total population under study. The mean age and teaching experience of the respondents were $33.2(\mathrm{SD}=7.46$ years) and 5.08 years $(\mathrm{SD}=5.19$ years) respectively. Table 1 and Table 2 describe the sample across academic rank, level of education, and gender.

\subsection{Instruments}

Self-report measures were developed and partially adapted to assess workplace variables [i.e. Instructors perception of distributive (allocational) justice and procedural justice, and perceived quality of relationship between leaders' (deans and heads of departments) and staff members (instructors)], satisfaction with salary organizational commitment, organizational citizenship behavior (OCB), overall job satisfaction, and vulnerability to external and internal brain drain. Further, a questionnaire was developed to elicit personal information about the study participants. The details are now in order.

\section{Work environment}

Instructors' perceptions of their work environment operationalized as the degree of fairness of organizational justice and leader-subordinate relationships. (1) Fairness perception - focuses on two dimensions of instructors' perception (a) procedural justice (i.e. transparency and participatory decision-making) and, (b) distributive justice (i.e. allocation of workload and benefits). In each case, two-items were developed to assess these constructs. (2) Leader-Member-Exchange (LMX) Measure - assessed based on two items taping instructors' views of the quality of relationship with institutional leaders were developed to assess leader behavior. Thus, to assess these work environment factors a total of six items were used. The response set was based on five-point scale ranging from ("very true" to "not at all true"). The internal consistency reliability of the overall 6-item measure was found to be acceptable (alpha $=.65)$.

\section{Satisfaction with salary}

Satisfaction with salary was operationalized as "Instructors' perception of salary adequacy (considering the type of work they are doing) and comparability of the salary amount with salaries of their counterparts working in other organizations. Two items were used to assess both factors rated in five-point Likert -type.

\section{Organizational commitment}

Organizational commitment was assessed with a translated and adapted version of Meyer and Allen (1991) affective organizational commitment dimension; since, affective commitment maintains behavioral direction where there is little expectation of formal rewards (Allen \& Meyer 1996). Sample items include: "The College/University has a great deal of personal meaning to me". The rating of items was made based on a five-point Likert-type scale ranging from "Strongly agree" to "Strongly disagree". The internal consistency reliability of the adapted sub-scale was found to be high (alpha $=.74)$.

\section{Vulnerability to brain drain}

The criterion variables were: Vulnerability to external brain drain (VEBD) and internal brain drain (VIBD). (a) Vulnerability to external brain drain conceptualized as intention to stay in a Western/Industrialized Country after completing a further study or research. (b) Vulnerability to internal brain drain is defined as intent to leave the University to another organization (to the public sector or NGOs). The two variables were measured based on a single-item "Yes" or "No" type question requesting the respondents to show their intent or non-intent.

\section{Overall job satisfaction}

Instructors' level of overall job satisfaction was measured based on a single-item: "When all things about your job are considered, how satisfied are you?" To that effect, a Likert-type scale range from "Very Satisfied" to "Very Dissatisfied" was used. The reason for using the single-item measure of job satisfaction was that it was both effective and less time consuming (Nagy 2002).

\subsection{Method of data analysis}

The methods of data analyses used in this study comprised univariate, bivariate and multivariate procedures. Specifically, it comprised descriptive statistics, zero-order correlation, F-test, and moderated hierarchical logistic regression. Non-parametric statistical techniques were also used to test statistical significance of the overall rankings of 'Pull' and 'Push' factors of internal and external brain drain respectively. Accordingly, the Friedman Two-Way ANOVA by ranks was employed to determine the significance of the rankings and the Wilcoxon Matched-Pairs Signed Ranks Test which is analogues with a Post hoc pair-wise mean comparison in ordinary ANOVA to compare a pair of rankings. Data entry and analyses were performed using SPSSWIN version 10. 


\section{Results}

In this section, first the results of the descriptive statistics will be presented to get an impression about the data followed by the inter-correlation results to identify important variables to be later included in the Logistic Regression. Finally, the result of the Friedman two-way ANOVA will be in order to find out the degree of independence of the rankings of the "pull" and "push" factors that underpin vulnerability to internal and external brain drain.

\subsection{Descriptive results}

According to the analysis, intent to remain abroad, perceptions of the work environment, salary amount, organizational commitment and intent or non-intent to leave academia (i.e. internal brain drain) and migrate (i.e. external brain drain) are described by academic rank. As depicted in Tables: 3 and 4, majority of the respondents said they would return $(61.8 \%)$ after completing their training or research leave in a Western/Industrialized country, while still a good proportion $(38.2 \%)$ said that they would staying on. With regard to vulnerability to internal brain drain (VIBD), the overwhelming majority (68\%) seem to wait for a convenient time. What is different about the above data is that more senior people want to leave the university system ( 5 out of 9 assistant professors and above; 38 out of 55 lecturers). But this was not the case when it comes to planning to migrate to a Western country ( 2 out of 8 assistant professors, and 18 out of 55 lecturers).

As shown in Table 6 distributive justice (i.e. perceptions of fairness in terms of allocation of workload, distribution of benefits) and the quality of staff-officials relationships did not bring about variations among instructors despite differences in academic rank. Similarly, no differences was evident in relation to procedural justice i.e. differences in perceiving their participation in important decisions in the university affairs. Specifically speaking about instructors' perception of procedural justice, one can observe from the overall average score (Mean $=6.54$ and $\mathrm{SD}=1.52)$ that instructors are in ambivalent situation. Hence, the respondents generally reported that there was neither a fair practice nor can they full heartedly claim that the leadership ensured transparent and participatory decision-making (Mean $=5.57$ and $\mathrm{SD}=1.71$ ). In contrast, Leader-Member-Exchange (LMX) was the most favorably perceived work environment factor (Mean $=8.42$ and $\mathrm{SD}=1.23$ ). It focused on quality of relationships between instructors and immediate superiors in a work context i.e. department heads and faculty deans. In general, faculty members were not that dissatisfied in their relationships with their immediate bosses.

\subsection{Results of the multivariate analyses}

In this section, an attempt is made to unravel those factors which predict vulnerability to internal (VIBD) and external (VEBD) brain drain among the set of variables categorized under socio-demographic, work environment, salary, and affective job characteristics. To identify the variables with a significant predictive efficacy, a Logistic Regression (LR) procedure was used in three steps to compare the different models. This was done for two major reasons (1) The hierarchical procedure helps to reveal the effect of both group and individual variables and (2) reveal the increasing or declining effects via examining the changes in the amount of shared variance (McFadden's - $\mathrm{R}^{2}$ ) (Whitehead 1998; Cohen 1999).

\subsubsection{Predictors of internal brain drain}

As shown in Table 8, the Logistic Regression shows that socio-demographic variables have almost no predictive relationship with faculty intent or non-intent to leave the university (i.e. internal brain drain) with the exception of age (Wald $=3.14, \mathrm{p}<.10$ ) which showed a marginal significance. On the contrary, however, Model II indicates that work environment factors significant predictors of 'Vulnerability to Internal Brain Drain (VIBD)' with the high overall model fit (Model Chi-square $=16.86, \mathrm{p}<.001$ ). Further, the improvement Chi-square was found to be significant $(\chi 2=10.31, \mathrm{p}<.01)$ which portrays the overall fit of Model II accompanied by a marked increase in the percentage of correct prediction (Model I: \% correct prediction $=66.02$; Model II: \% correct prediction $=71.84 \%$ ). A closer look into the specific contributions disclosed that Procedural Justice (Model II: Wald $=6.14 ; \mathrm{p}<.01, d f=9 ;$ Model III: Wald $=6.12, \mathrm{p}<.01 ; d f=10)$ found to noticeably affect VIBD followed by Leader-Member-Exchange, (Model II: Wald = 3.65; $<<.05, d f=9 ;$ Model III: Wald = 3.67, $\mathrm{p}<.10, d f=10$ ) and perceived fairness of leadership with respect to distributive justice (Model II: Wald $=2.91 ; \mathrm{p}<.10, d f=9$; Model III: Wald $=2.73, \mathrm{p}<.10, d f=10$ ). However, salary adequacy and comparability were also included to examine their possible effects. Thus, both variables were not come out as important predictors in the presence of other work environment factors. Similarly, Model III added Overall Job Satisfaction into the equation, no meaningful increment has been observed since both the Improvement Chi-square (Chi-square $=.026, n s$ ) and the percentage of correct classification did not show increments (see: Table 8) 


\subsubsection{Predictors of external brain drain}

As indicated in Table 9, a second set of Logistic Regression Models were fitted to find a predictive relationship of socio-demographic, work environment, and work attitude variables with intent formation to migrate to a western country (external brain drain). The results reveal that socio-demographic variables have a limited role in these predictions even though education $(\mathrm{r}=-.25, \mathrm{p}<.01)$ and academic rank $(\mathrm{r}=-.23 ; \mathrm{p}<.01)$ were inversely and significantly correlated with vulnerability to external brain drain (see: Table 7). In other words, increased education and academic rank bolsters the likelihood of intending to remain while at the same time, respondents' age associated with intending to return home. However, the strength of social and demographic factors were found to be weaker when entered into the models (Model I: Model Chi-Square $=8.08, d f=5$; $n s$ ). Nonetheless, intention to leave - i.e. vulnerability to internal brain drain (Model II Wald $=12.93, \mathrm{p}<.001$; Model III: Wald = $12.18, \mathrm{p}<.001)$ and organizational citizenship behavior (OCB) (Model III: Wald= 6.26, p < .05) demonstrated significant predictive relationship with vulnerability to external brain drain. The OCB scores which were added into the equation in step three revealed its substantial contribution to the overall model improvement (Improvement Chi-Square $=8.08, \mathrm{p}<.001, d f=2$ ). Furthermore, it markedly contributed to the overall model-fit (Model Chi-square $=35.43, \mathrm{p}<.001, d f=9$ ) and in the percentage of correct prediction (Percentage of correct prediction; Model $I=66.02 \%$; Model $I I=66.61 \%$; Model $I I I=76.47 \%$ ). The role of overall job satisfaction (Model III: Wald $=.97, n s$ ) remains to be marginal however.

Taken together, the results demonstrated that the two criterion variables namely, VIBD and VEBD found to have separate causes. Consistent with their conceptual distinctiveness, the empirical results confirmed that internal brain drain is affected more by work environment variables within the University. In contrast, the dimensions of work environment have little role if any, to play in terms of facilitating external brain drain. What is more interesting in the later findings is the crucial role of faculty organizational citizenship behavior (OCB) i.e. the level of sense of belongingness, loyalty and commitment to their university. Thus, it is quite clear that in a situation where instructors' affective attachment to their university is not optimal, there would be low likelihood of curtailing external brain drain.

\subsubsection{Reasons for internal brain drain}

Subsequent to determining the proportion of respondents who plan to leave the university, it was also attempted to find how respondents rank-ordered the "push" factors which gave rise to intending career change. The results of these analyses are presented in Tables: 10 and 11. Accordingly, Table 11 shows the list of factors which were rank-ordered as push factors responsible for discouraging faculty members to opt for employment outside the University. Among the five perceived push factors "Bad salary scale", "Unfavorable working conditions", and "Dissatisfaction with college administration" ranked first, second and third in that order. However, "Limited opportunities for career development" and "Lack of research fund" found to be the fourth and fifth in the ranking. A further analysis of the overall rankings (see: Table 11) revealed that the respondents variations in rating the "push factors" were beyond chance $\left(\chi^{2}=214.02, \mathrm{p}<.00001, d f=4\right)$. Following these significant differences of the mean rankings a Wilcoxon Matched-pairs Signed-Rank Test was performed to find if there were meaningful differences between any two pair of mean ranks. Accordingly, only the ranking of "Unfavorable working conditions (UWC) and "Dissatisfaction with the college administration (DCA)" were found not to differ to statistically significant extent. Meaning, the respondents attached more or less equal importance to the later two factors as discouraging aspects working in the University.

\subsubsection{Reasons for external brain drain}

Based on the empirical grounds provided in the literature, in the present study, the 40 (39\%) respondents who endorsed staying in a Western/Industrialized country after completing their studies or research were also requested to rank-order the "pull factors of brain drain". Accordingly, the four pull factors that were identified in the literature considered pertinent.

As shown in Table 12, the respondents' rankings of the above mentioned "Pull factors", the chi-square test revealed that the respondents did not significantly differ in their opinion for being attracted by "Attractive salary" $\left(\chi^{2}=5.60, d f=3 ; n s\right)$ and "Better career opportunities" $\left(\chi^{2}=6.80, d f=3\right.$; $\left.n s\right)$. This is because; both factors did not vary in terms of rankings to a significant degree. However, meaningful variations were observed in ranking the other two pull factors. Namely: "Better working conditions" $\left(\chi^{2}=19.4, d f=3 ; \mathrm{p}<.0001\right)$ and "Political Stability of the host country" $\left(\chi^{2}=9.00, d f=3 ; \mathrm{p}<.05\right)$. A closer look at Table 12 further illustrates that "Better working conditions" was endorsed by majority of the respondents (Rank $1=42.5 \%$ and Rank $2=$ $40.5 \%$ ) revealing that good working conditions persuade most academics to migrate. While on the other hand, political stability of the host country was found to be the less important reason. In addition, the Freidman 
Two-Way ANOVA by ranks (see: Table 13) confirmed that "Better Working conditions" (Mean Rank = 1.44; Rank = 1), "Attractive Salary", (Mean Rank = 2.03; Rank = 2) "Better career opportunities", (Mean Rank = 3.13; Rank = 3) and "Political Stability" (Mean Rank =3.41; Rank =4) received the rankings ranging from 1 to 4 in that order. Further, the ordering of the factors is based on true differences in terms of the level of importance attached to these pull factors. This once again confirms the findings that working condition and salary are the first two most important pull factors to be followed by better career expectation and political stability.

\section{Discussion and Conclusions}

The present study assessed some of the factors that affect vulnerability to both internal and external brain drain. Specifically, it attempted to find the extent to which different sets of variables ranging from socio-demographic factors to workplace and affective job-related variables play a role in influencing faculty intent formation. Precisely, the study had two major purposes. First, it tried to determine which set (s) of variables significantly predict vulnerability to internal and external brain drain. Secondly, it attempted to find which "push" and "pull" factors are salient in encouraging internal and external brain drain respectively.

It turned out that the two types of vulnerability to brain drain are predicted by different set of variables. Accordingly, VIBD refers to instructors' intent to seek employment in another organization leaving the university was significantly predicted by work environment factors. More specifically, procedural justice, distributive justice, and leader-member-exchange (LMX) are found to play a meaningful role in both encouraging and discouraging faculty members' future career decisions. Nonetheless, no significant predictive relationship was observed with respect to salary adequacy and salary comparability. This implies that the fairness of university leadership and good governance specially related to fairness in terms of ensuring the participation of academic staff in important decision making that affect them (like setting rules, regulations, and policies), distribution of workload and benefits, appointments to official positions, scholarship, research and sabbatical leaves are critical to retain its highly experienced and young academics. Further, the finding related to the predictive significance of LMX is more to do with the presence or absence of good collegial relations, particularly between academic staff and university leaders.

On the other hand, external brain drain was found to be predicted by vulnerability to internal brain drain (Wald = $12.61, \mathrm{p}<.001$ ), and organizational citizenship behavior (Wald $=6.26, \mathrm{p}<.05$ ). This shows that academics who were intending to stay in the university also envisage returning back to their university after completing their study and research abroad. Further, intention to return (from abroad) after completing study/research is strongly associated with instructors' level of organizational citizenship behavior (OCB) i.e. those with high organizational citizenship behavior tend to return while those with low OCB tend to look for employment or other options in a foreign land.

Instructors' also ranked the "push" factors that discourage them to seek for non-university employment and the "pull" factors that encourage them to aspire migrating to industrialized West. The first two top rankings were found to be the same for both types of brain drain. These are related to salary and working conditions. This, in turn, suggests that instructors who are contemplating to leave complained that the salary is low and the existing working condition is not favorable. Specifically speaking about the respondents' rankings of the "push" factors vis-à-vis internal brain drain, were "Bad salary scale", "Unfavorable working conditions", and "Dissatisfaction with the college administration", "Opportunities for career development" and "Lack of Research fund" in that order. The findings further confirms that desire to look for employment in other organizations found to result from low perception of fairness in terms of distributive justice and procedural justice, and less friendly leader-member-exchange (LMX). Moreover, instructors who harbor the plan of staying in an industrialized country tend to be younger, less likely to attain there terminal degrees and served fewer years. With regard to the reasons, they mentioned "Attractive Salary" and "Better working conditions" as their first two top attracting or pulling factors while "Better career opportunity" and "Political stability of the host country" ranked third and fourth.

These results are consistent with the contention of scholars who studied the antecedent factors of brain drain in African setting (e.g., Shinn 2002; Teferra, S. 2000; Siethi 1999; Shibeshi 1995) in general, and in the Ethiopian context (e.g., Aredo 2000; Teferra, S. 1992; 2000) in particular. Taken together, even though vulnerability to "internal" and "external" brain drain is found to be predicted by two distinct set of variables (factors), they have a common denominator, namely: Salary and working condition. Understandably, improving salary structure and offering better working condition is closely linked with economic development that can carry an additional burden in budget terms. This does not, however, mean that an optimal scenario that takes account of the existing economic condition is unthinkable. In the other end of the spectrum, there are areas which do not require 
additional finance. This is improving the work environment in terms of fairness in allocation of responsibilities and benefits and democratizing college/university administration at least can help mitigate internal brain drain.

With regard to the democratization of HEIs in Ethiopia, significant steps have been taken particularly in terms of improving the old-fashioned feudalistic instructor - student relations. While on the other hand, the "democratization" unfairly used against instructors by some students. Instances of personal attack and humiliation during a face-to-face evaluation of the former by the later (which is referred as 'Gemgema' in Amharic) were rampant and still fresh in the minds some professors who witnessed others or who were victims themselves. On their part, though getting students' reactions about their teaching is desirable, they were resentful of the manner in which criticisms were uttered and words of criticism were chosen. Though this mechanism was later abandoned, a lesson has to be learned not to repeat past mistakes. Majority of the instructors participated in the present study expressed concern that the manner in which their performance is assessed by students need to target improvement in learning and teaching rather than individual faculty members. It could be argued that such negative turn of events can create lots of dissatisfaction among staff by worsening the already vanishing attraction of pursuing a career in higher education institutions. Hence, readdressing the plights of academics at their workplace should also means to do away with humiliating treatment and put in place a truly democratic environment based on mutual respect and scholarly pursuit.

The other important factor in terms of mitigating external brain drain is to strictly consider options that facilitate organizational citizenship behavior (OCB). On the one hand, OCB bolsters instructors' commitment to their university, and increase the likelihood that they would stay in the system despite low salary scale. In other words, OCB is not something associated with monetary rewards (e.g., Posdakoff et al. 2000; Hannam \& Jimmieson 2002; Semela 2005). Most importantly, it is an outcome of affective emotional attachment with their employing organization. In other words, strong OCB still presupposes ensuring favorable institutional internal environment that fosters shared organizational values and a sense of ownership among its faculty.

\section{References}

Adebayo, A. (2010). Brain Drain-Brain Gain: Leveraging the Nigerian Diaspora for the Revitalization of Nigerian Higher Education. Paper Presented at the 25th Conference of the Association of Vice Chancellors of Nigerian Universities, held at Osun State University, Osogbo, on April 19-22, 2010.

Allen, J. \& Meyer, N. (1996). Affective, continuance and normative commitment to the organization: An examination of a construct validity. Journal of Vocational Behaviour, 49, 252-276.

Aredo, D. (2000). The brain drain from Ethiopia. Ethiopian Development Forum, 1(3), 1-19.

Debub University. (2003). Ten-Years Strategic Plan, Draft Document, September 2003, Awassa, Ethiopia.

Economy Watch. (2010). Ethiopia: Economic statistics and indicators. [Online] Available: http://www.economywatch.com/economic-statistics/country/Ethiopia (10/1/2010).

Hannam, R. \& Jimmieson, N. (2002). The relationship between extra-role behaviors and job-burnout for primary school teachers: A preliminary model and development of an organizational citizenship behavior scale. [Online] Available: http:// www. Aare.edu.au/02pap/han02173.htm.

Meyer, J \& Allen, N. (1991). A three-component model of organizational commitment. Human Resource Development Review, 1(1), 61-89.

Meyer, J.P., Allen, N.J. \& Smith, C.A. (1993). Commitment to organizations and occupations: extensions and test of a three-component conceptualization. Journal of Applied Psychology, 78(4), 538-551.

Ministry of Education (MoE). (2003). Education sector development program (ESDP III): consolidated national performance report - 2001/2002. Addis Ababa, Ministry of Education.

Ministry of Education (MoE). (2009). Education statistics annual abstract: 2007/8. Addis Ababa, Ministry of Education.

Miwiria, K. (2003). University governance and university-state relations. In Teffera, Damtew and Altbach, Phillip (eds.). African Higher Education: An International Reference Handbook, pp.32-43, Bloomington, Indiana: University of Indiana Press.

Mohamoud, A.A. (2005). Reversing the brain drain in Africa: Harnessing the intellectual capital of the Diaspora for knowledge development in Africa. SAHAN, Amsterdam, Sept. 2005.

Nagy, M.S. (2002). Using a single-item approach to measure facet job satisfaction. Journal of Occupational Psychology, 75, 77-86. 
NASAC. (2009). Brain drain in Africa: Joint statement by the Network of African Science Academies (NASAC).

Obong, Q.U. (2004). Academic dilemmas under neo-liberal education reforms: A review of Mekerere University, Uganda. In Zeleza, Paul Tiyambe \& Olukoushi, Adebayo (eds.) African Universities in Twenty-first Century, PP. $108-125$.

Olango, M. \& Semela, T. (2000). Determinants of decision to leave or stay in the teaching profession. The Ethiopian Journal of Education, 20(1), 1-23.

Posdakoff, P., Mackenzie, S., Paine, B. \& Bacharach, D. (2000). Organizational citizenship behavior: A critical review of theoretical and empirical literature and suggestions for future research. Journal of Management, 26(3), 513-563.

Sall, E., Lebeau, L. \& Kassimir, R. (2003). The public dimension of the university in Africa. Journal of Higher Education in Africa, 1(1), 126-148.

Saxenian, A. (2005). From brain drain to brain circulation: Transnational communities and regional upgrading in India and China. Studies in Comparative and International Development, 40 (2), 35-61.

Semela, T. \& Ayalew, E. (2008). Ethiopia. In: Damtew Teferra and Jane Knight (Eds.) African Higher Education: The International Dimension. Center for International Higher Education (CIHE), Boston College, USA and Association of African Universities (AAU), Accra, Ghana. ISBN: 978-99-8858-940-9.

Semela, T. (2003). Effects of working conditions on teachers' plan to stay in their career in Sub-Saharan Africa: The Case of Southern Ethiopia. A PhD Dissertation, Faculty of Social and Behavioral Sciences, University of Tübingen, Germany.

Semela, T. (2004). Perception of work environment in institutes of higher learning in Ethiopia. A search for antecedents of organizational commitment and turnover among Debub University instructors. Ethiopian Journal of Higher Education, 1(2), 33-60.

Semela, T. (2005). Extra-role behavior in educational organizations in Sidama Zone southern Ethiopia: Implications for School Effectiveness. Eastern African Social Science Research Review, 21 (2), 15-38.

Sethi, M. (2000). Return and reintegration of qualified African nationals. Paper presented at ECA's regional conference on brain drain and capacity building in Africa, 22-24 February, Addis Ababa.

Shibeshi, A. (1995). Problems of staff recruitment and retention in higher education institutions in developing countries. In the Proceedings of the National Workshop on Strengthening Educational Research, Addis Ababa University, IER.

Shibeshi, A., Mekonnen, D., Semela, T. \& Endawoke, Y. (2009). Assessment of science education quality indicators in Addis Ababa, Bahir Dar, and Hawassa Universities. In: Quality of Higher Education in Ethiopian Public Institutions, pp. 161-264, Forum for Social Studies, Addis Ababa, Ethiopia.

Shinn, D.H. (2002). Reversing the Brain Drain in Ethiopia. A paper presented to the Ethiopian North American Health Professionals Association, Nov. 23, 2002, Alexandria, Virginia, USA.

Teferra, D. (2004). Brain Circulation: Unparalleled Opportunities, Underlying Challenges, and Outmoded Presumptions. Paper prepared for the Symposium on International Labor and Academic Mobility: Emerging Trends and Implications for Public Policy. October 21st and October 22nd 2004. World Education Services. Toronto, Ontario, Canada.

Teferra, S. (1992). Brain-drain among academicians in two higher learning institutions in Ethiopia. The Ethiopian Journal of Education, 13(2), 20-30.

Teferra, S. (2000). The causes and magnitude of brain-drain in higher education institutions with a particular reference to AAU: "Go West, Young Man (GO)". Ethiopian Development Forum, 1(3), 20-30.

Teffera, D. (2000). "Revisiting the doctrine of human resource mobility in information age". Paper presented at regional conference on brain drain and capacity building in Africa, 22-24 February, Addis Ababa, Ethiopia.

Whitehead, J. (1998). Willingness to pay for bass fishing trips in the Carolinas. Department of Economics, East Caroline University (Published Electronically).

Wole, D. (2002). The pre-dominance of different sources of stress among teachers in government senior high schools of Addis Ababa. The Ethiopian Journal of Education, 22(1), 1-32. 
Wondimu, H. (2003). "Ethiopia": In Teffera, Damtew and Altbach, Phillip (eds.). African Higher Education: An International Reference Handbook, pp.316-325, Bloomington, Indiana: University of Indiana Press.

World Bank. (2003). Higher education development for Ethiopia: Perusing the vision. World Bank Sector Study. November 20, 2003.

Zeleza, P. T. (2004). Academic freedom in the neo-liberal order: Governments, globalization, governance, and gender. Journal of Higher Education in Africa, Vol. 1, No. 1, PP. 149-194.

Table 1. Participants' level of education by gender

\begin{tabular}{|lccccc|}
\hline & \multicolumn{5}{c|}{ Gender } \\
\cline { 2 - 5 } \multicolumn{1}{c}{ Education } & Male & Female & Total & $\%$ \\
\hline PhD & 4 & 1 & 5 & 4.9 \\
M.A./MSc./ & MD & 53 & 2 & 55 & 53.4 \\
Speciality & & & & & \\
MD/DVM & 7 & - & 7 & 6.7 \\
B.A./B.Sc. & 16 & 7 & 23 & 22.3 \\
Diploma & 13 & - & 13 & 12.6 \\
\hline Total & $\mathbf{9 3}$ & $\mathbf{1 0}$ & $\mathbf{1 0 3}$ & $\mathbf{1 0 0}$ \\
\% & $\mathbf{9 0 . 3}$ & $\mathbf{9 . 7}$ & $\mathbf{1 0 0}$ & \\
\hline
\end{tabular}

Table 2. Participants' academic rank by gender

\begin{tabular}{|lcccc|}
\hline \multirow{2}{*}{ Academic Rank } & \multicolumn{3}{c|}{ Gender } \\
\cline { 2 - 5 } & Male & Female & Total & $\%$ \\
\hline Associate Professor & 2 & - & 2 & 1.9 \\
Assistant Professor & 6 & 1 & 7 & 6.8 \\
Lecturer & 53 & 2 & 55 & 53.4 \\
Assistant Lecturer & 4 & - & 4 & 3.9 \\
Graduate Assistant & 15 & 7 & 22 & 21.4 \\
Technical Assistant & 13 & - & 13 & 12.6 \\
\hline Total & $\mathbf{9 3}$ & $\mathbf{1 0}$ & $\mathbf{1 0 3}$ & $\mathbf{1 0 0}$ \\
\hline
\end{tabular}

Table 3. Intent to stay or return after completing training or research abroad

\begin{tabular}{|lcccc|}
\hline \multirow{2}{*}{ Education } & \multicolumn{3}{c|}{ Intent } \\
\cline { 2 - 5 } & Stay & $\begin{array}{c}\text { Will be } \\
\text { back }\end{array}$ & Total & $\%$ \\
\hline PhD & $1(1.5)$ & $7(5)$ & 8 & 7.8 \\
M.A./MSc./ MD + Speciality & $17(19.5)$ & $34(31.5)$ & 54 & 50 \\
MD/DVM & $2(2.7)$ & $5(4.3)$ & 7 & 6.9 \\
B.A./B.Sc. & $10(8.8)$ & $13(14.2)$ & 23 & 22.3 \\
Diploma & $9(5.0)$ & $4(8.0)$ & 13 & 12.7 \\
\hline Total & $\mathbf{3 9}$ & $\mathbf{6 3}$ & $\mathbf{1 0 2}$ & $\mathbf{1 0 0}$ \\
\% & $\mathbf{3 8 . 2}$ & $\mathbf{6 1 . 8}$ & $\mathbf{1 0 0}$ & \\
\hline
\end{tabular}

$\chi^{2}=7.13, d f=4 ; n s$ 
Table 4. Vulnerability to external brain drain (VEBD) by academic rank

\begin{tabular}{|lcccc|}
\hline \multirow{2}{*}{\multicolumn{1}{c}{ Academic Rank }} & \multicolumn{4}{c|}{ Intent } \\
\cline { 2 - 5 } & Stay & Return & Total & $\%$ \\
\hline Assistant Professor $>$ & 2 & 6 & 8 & 6.8 \\
Lecturer & 18 & 37 & 55 & 53.4 \\
Assistant Lecturer & 1 & 3 & 4 & 3.9 \\
Graduate Assistant & 9 & 13 & 22 & 21.4 \\
Technical Assistant & 9 & 4 & 13 & 12.6 \\
\hline Total & $\mathbf{3 9}$ & $\mathbf{6 3}$ & $\mathbf{1 0 3}$ & $\mathbf{1 0 0}$ \\
\hline
\end{tabular}

$\chi^{2}=6.4, d f=4 ; n s$

Table 5. Vulnerability to internal brain drain (VIBD) by academic rank

\begin{tabular}{|c|c|c|c|c|c|}
\hline \multirow[t]{2}{*}{ Academic Rank } & \multicolumn{2}{|r|}{ Leave } & \multicolumn{2}{|l|}{ Stay } & \\
\hline & $\mathbf{N}$ & $\%$ & $\mathbf{N}$ & $\%$ & Chi-square \\
\hline Assist. Prof $>$ & 5 & 6.1 & 4 & 2.9 & \\
\hline Lecturer & 38 & 37.4 & 17 & 17.6 & $3.07 *$ \\
\hline Assist Lecturer < & 1 & 2.7 & 3 & 1.3 & \\
\hline Graduate Assistant & 15 & 19.5 & 7 & 7.0 & \\
\hline Technical Assistant & 11 & 8.8 & 2 & 2.2 & \\
\hline Total & 70 & 68 & 33 & 32 & \\
\hline
\end{tabular}

$\chi^{2}=3.07, \mathrm{p}<.05, d f=1$

Table 6. Means, SD, and F-statistics of work environment dimensions by Academic Rank

\begin{tabular}{|lccccccccc|}
\hline Academic Rank & \multicolumn{2}{c}{ Distributive Justice } & \multicolumn{3}{c|}{ LMX $^{\mathbf{a}}$} & \multicolumn{3}{c|}{ Procedural Justice } \\
& M & SD & F & M & SD & F & M & SD & F \\
\hline Assist. Prof $>$ & 6.22 & 1.30 & & 8.56 & .88 & & 5.78 & 1.92 & \\
Lecturer & 6.83 & 1.59 & & 8.55 & 1.30 & & 5.42 & 1.61 & \\
Assist Lecturer $<$ & 5.88 & 1.66 & $1.35(n s)$ & 7.81 & 1.41 & $.57(n s)$ & 5.58 & 1.90 & 1.43 \\
& & & & & & & & & $(n s)$ \\
Technical Assistant & 6.85 & .99 & & 8.92 & .95 & & 6.08 & 1.55 & \\
Total & 6.54 & 1.52 & & 8.41 & 1.23 & & 5.57 & 1.71 & \\
\hline
\end{tabular}

$n s=$ not significant ${ }^{\text {a }}$ LMX $=$ Leader-Member-Exchange 


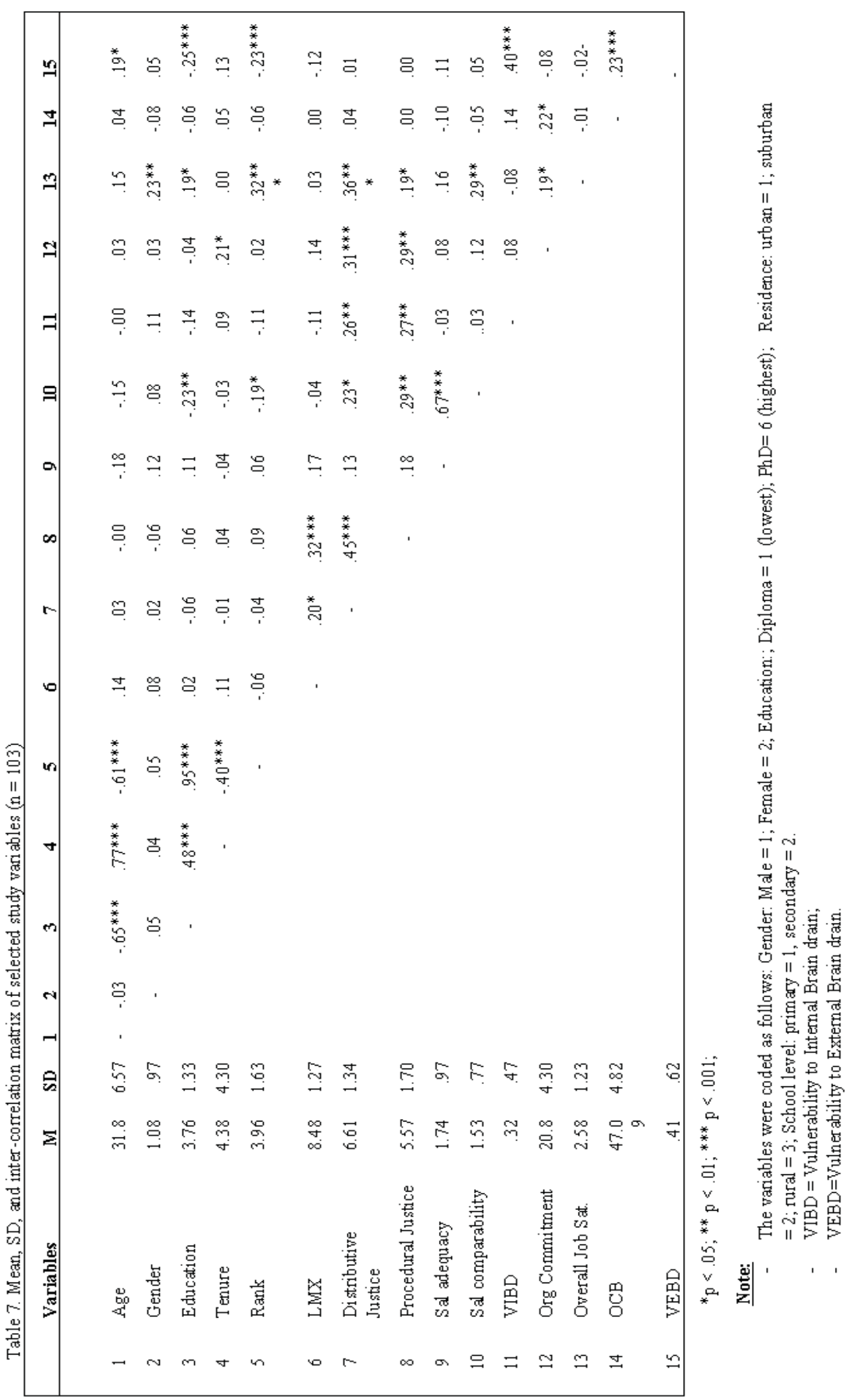


Table 8. Logistic regression models of vulnerability to internal brain drain (VIBD)

\begin{tabular}{|c|c|c|c|c|c|c|}
\hline Variables $^{\mathrm{a}}$ & \multicolumn{2}{|c|}{ Model I } & \multicolumn{2}{|c|}{ Model II } & \multicolumn{2}{|c|}{ Model III } \\
\hline & B & Wald & B & Wald & B & Wald \\
\hline \multicolumn{7}{|l|}{ Demographic var. } \\
\hline Age & $-12 *$ & 3.14 & $-.13^{*}$ & 3.05 & $-.13^{*}$ & 3.06 \\
\hline Education & .15 & 1.43 & .03 & .00 & .04 & .00 \\
\hline Rank $^{\mathrm{b}}$ & .65 & 1.52 & .42 & .68 & .42 & .68 \\
\hline Tenure & .10 & .10 & .14 & 2.79 & -.067 & -.125 \\
\hline \multicolumn{7}{|l|}{ Work environment } \\
\hline Procedural Justice & - & - & $.49 * * *$ & 6.14 & $.49 * * *$ & .6 .12 \\
\hline $\mathrm{LMX}^{\mathrm{c}}$ & - & - & $.46^{* *}$ & 3.65 & $.46^{*}$ & 3.67 \\
\hline Leadership Fairness & - & - & $.36^{*}$ & 2.91 & .37 & 2.73 \\
\hline \multicolumn{7}{|l|}{ Salary } \\
\hline Adequacy & & & -.12 & .12 & -.12 & .11 \\
\hline Comparability & - & - & -.27 & .34 & -.26 & .32 \\
\hline Overall Job satisfaction & - & - & - & - & .05 & .03 \\
\hline Chi-square & \multicolumn{2}{|c|}{6.15} & \multicolumn{2}{|c|}{$16.86^{* * * *}$} & \multicolumn{2}{|c|}{$17.12 * * *$} \\
\hline$d f$ & \multicolumn{2}{|c|}{4} & \multicolumn{2}{|c|}{9} & \multicolumn{2}{|c|}{10} \\
\hline Improvement Chi-square & \multirow{2}{*}{\multicolumn{2}{|c|}{-}} & \multicolumn{2}{|c|}{$10.31 * * *$} & \multicolumn{2}{|c|}{0.26} \\
\hline$d f$ & & & & & & \\
\hline$\%$ Correctly predicted & \multicolumn{2}{|c|}{66.02} & \multicolumn{2}{|c|}{$71.84 \%$} & \multicolumn{2}{|c|}{$71.84 \%$} \\
\hline
\end{tabular}

$* \mathrm{p}<.10 ; * * \mathrm{p}<.05 ; * * * \mathrm{p}<.01$

Note:

${ }^{\mathrm{a}}$ The variables below were coded as follows: Gender: Male $=1 ;$ Female $=2 ;$ Education: $\mathrm{PhD}=6 ; \mathrm{Mphil}=5 ; \mathrm{MA}$. $/ \mathrm{MSc}=4 ; \mathrm{MD}=3$, B.A. $/ \mathrm{BSc}=2$; Diploma $=1$;

${ }^{\mathrm{b}}$ Academic Rank: Associate Prof=7; Assistant Prof. = 6; Lecturer: $=5$; Assistant Lecturer =4; Graduate Assist II $=3$; Graduate Assist I $=2$; and Technical Assist $=1$

${ }^{c} \mathrm{LMX}=$ Leader - Member - Exchange. 
Table 9. Logistic regression models of vulnerability to external brain drain (VEBD)

\begin{tabular}{|c|c|c|c|c|c|c|}
\hline Variables & \multicolumn{2}{|c|}{ Model I } & \multicolumn{2}{|c|}{ Model II } & \multicolumn{2}{|c|}{ Model III } \\
\hline & B & Wald & B & Wald & B & Wald \\
\hline \multicolumn{7}{|l|}{ Demographic var. } \\
\hline Age & .025 & 19 & .066 & 1.05 & 0.63 & .92 \\
\hline Gender & .845 & .896 & .622 & .41 & 1.08 & .99 \\
\hline Education & -.62 & 1.42 & -.309 & .34 & -.529 & .82 \\
\hline Rank & .07 & .27 & .078 & .01 & .254 & .08 \\
\hline Tenure & -.01 & .01 & -.023 & .07 & -.004 & .001 \\
\hline \multicolumn{7}{|l|}{ Work attitude } \\
\hline Organizational comm. & - & - & -.061 & .93 & $-.121^{*}$ & 2.85 \\
\hline VIBD & - & - & $2.49 * * *$ & 12.93 & $2.61 * * *$ & 12.18 \\
\hline Overall Job Satisfaction & & & - & - & -.21 & .97 \\
\hline OCB & - & - & - & - & $.15^{* *}$ & 6.26 \\
\hline Chi-square & \multicolumn{2}{|c|}{8.04} & \multicolumn{2}{|c|}{$27.35^{* * *}$} & \multicolumn{2}{|c|}{$35.43 * * *$} \\
\hline$d f$ & \multicolumn{2}{|c|}{5} & \multicolumn{2}{|c|}{7} & \multicolumn{2}{|c|}{9} \\
\hline Improvement Chi-square & \multirow{2}{*}{\multicolumn{2}{|c|}{-}} & \multicolumn{2}{|c|}{$19.31 * * *$} & \multicolumn{2}{|c|}{$8.08^{* *}$} \\
\hline$d f$ & & & \multicolumn{2}{|c|}{2} & \multicolumn{2}{|c|}{2} \\
\hline$\%$ Correctly predicted & \multicolumn{2}{|c|}{66.02} & \multicolumn{2}{|c|}{$69.61 \%$} & \multicolumn{2}{|c|}{$76.47 \%$} \\
\hline
\end{tabular}

$* \mathrm{p}<.10 ; * * \mathrm{p}<.05 ; * * * \mathrm{p}<.001$

Note:

${ }^{\mathrm{a}}$ The variables below were coded as follows: Gender: Male $=1 ;$ Female $=2 ;$ Education: $\mathrm{PhD}=6$; Mphil= 5; MA . $/ \mathrm{MSc}=4 ; \mathrm{MD}=3$, B.A. $/ \mathrm{BSc}=2$; Diploma $=1$;

${ }^{\mathrm{b}}$ Academic Rank: Associate Prof=7; Assistant Prof. $=6$; Lecturer: $=5$; Assistant Lecturer $=4$; Graduate Assist II $=3$; Graduate Assist I $=2$; and Technical Assist $=1$

${ }^{\mathrm{c}} \mathrm{OCB}=$ Organizational Citizenship Behavior

Table 10. Ranking of "Push" factors for internal brain drain (VIBD)

\begin{tabular}{|lccccc|}
\hline \multicolumn{7}{|c}{ Factors } & \multicolumn{5}{c|}{ Ranks* } \\
\hline & $\mathbf{1}$ & $\mathbf{2}$ & $\mathbf{3}$ & $\mathbf{4}$ & $\mathbf{5}$ \\
\hline Bad salary scale (BSAL) & $45(43.7)$ & $12(11.7)$ & $4(3.9)$ & $2(1.9)$ & $4(3.9)$ \\
Unfavorable working conditions (UWC) & $11(10.7)$ & $13(12.6)$ & $30(29.1)$ & $8(7.8)$ & $5(4.9)$ \\
Opportunities for career development (OPCD) & $3(2.9)$ & $17(16.5)$ & $8(7.8)$ & $25(24.3)$ & $13(12.6)$ \\
Lack of research fund (LRF) & $1(1)$ & $1(1)$ & $8(7.8)$ & $24(23.5)$ & $32(31.1)$ \\
Dissatisfaction with college adm. (DCA) & $7(6.8)$ & $26(25.2)$ & $17(16.5)$ & $6(5.8)$ & $11(10.7)$ \\
\hline
\end{tabular}

*All rankings are statistically significant

at $\mathrm{p}<.01$. 
Table 11. Pair-wise mean comparison of rankings of "Push" factors for internal brain drain [Wilcoxon Matched-pairs Signed-Rank Test $(\mathrm{N}=66)]$

\begin{tabular}{|lcccccccc|}
\hline $\begin{array}{l}\text { Push } \\
\text { factors }\end{array}$ & Rank $^{\mathrm{a}}$ & Mean Rank & SD & $\mathbf{1}$ & $\mathbf{2}$ & $\mathbf{3}$ & $\mathbf{4}$ & $\mathbf{5}$ \\
\hline BSAL & 1 & 2.15 & 1.05 & - & $-6.48^{*}$ & $-6.72^{* *}$ & $-6.83^{* *}$ & $-7.02^{* *}$ \\
UWC & 2 & 2.57 & 1.13 & - & -.85 & $-6.71^{* *}$ & $-7.02^{* *}$ \\
DCA & 3 & 2.77 & 1.24 & & & - & $-5.69^{* *}$ & $-6.87^{* *}$ \\
OPCD & 4 & 3.72 & 1.20 & & & - & $-6.26^{* *}$ \\
LRF & 5 & 4.68 & .86 & & & & - \\
\hline
\end{tabular}

${ }^{\mathrm{a}} \chi^{2}=214.02, \mathrm{p}<.00001, d f=4$; It is computed using Friedman's Two-Way ANOVA by Ranks to examine statistically significant difference in mean rankings of the Pull factors.

Table 12. Instructors' ranking of "Pull" factors for external brain drain

\begin{tabular}{|lccccc|}
\hline \multicolumn{7}{|c|}{ Pull factors } & \multicolumn{7}{c|}{ Ranks } \\
\hline & $\mathbf{1}$ & $\mathbf{2}$ & $\mathbf{3}$ & $\mathbf{4}$ & Chi-square \\
\hline Attractive Salary (ATSAL) & & & & & \\
Better working conditions (BWC) & $16(40)$ & $10(25)$ & $6(15)$ & $8(20)$ & 5.60 \\
Political stability of the host nation (POLSTA) & $17(42.5)$ & $16(40.5)$ & $7(17.5)$ & 0 & $19.4^{* * *}$ \\
Better career opportunity (BCOP) & $3(7.5)$ & $9(22.5)$ & $12(30)$ & $16(40)$ & $9.00^{* *}$ \\
\hline
\end{tabular}

$* \mathrm{p}<.10, * * \mathrm{p}<.05 * * * \mathrm{p}<.01$

Table 13. Pair-wise mean comparison of rankings based on Wilcoxon Matched-pairs Signed-Rank Test

\begin{tabular}{|lccccccc|}
\hline Pull factors & Mean Rank $^{\mathbf{a}}$ & Mean & SD & $\mathbf{1}$ & $\mathbf{2}$ & $\mathbf{3}$ & $\mathbf{4}$ \\
\hline ATSAL & 2.03 & 2.15 & 1.17 & - & $-3.77^{* *}$ & $-5.22^{* *}$ & $-5.50^{* *}$ \\
BWC & 1.44 & 1.75 & .74 & - & $-4.613^{* *}$ & $-5.014^{* *}$ \\
POLSTA & 3.41 & 3.03 & .97 & & - & $-2.646^{*}$ \\
BCOP & 3.13 & 2.85 & 1.07 & & & - \\
\hline
\end{tabular}

${ }^{\mathrm{a}} \chi^{2}=88.07, \mathrm{p}<.00001, d f=3$; It is computed using Friedman's Two-Way ANOVA by Ranks to examine statistically significant difference in mean rankings of the Pull factors. 